\title{
Combined interpretation of SkyTEM and high-resolution seismic data
}

\author{
Anne-Sophie Høyer ${ }^{\mathrm{a}, \mathrm{b}, *}$, Holger Lykke-Andersen ${ }^{\mathrm{a}}$, Flemming Jørgensen ${ }^{\mathrm{b}}$, Esben Auken ${ }^{\mathrm{a}}$ \\ a University of Aarhus, Department of Earth Sciences, Høegh-Guldbergs Gade 2, 8000 Aarhus C, Denmark \\ ${ }^{\mathrm{b}}$ Geological Survey of Denmark and Greenland (GEUS), Ø.Voldgade 10, 1350 København K, Denmark
}

\section{A R T I C L E I N F O}

Article history:

Received 17 May 2010

Received in revised form 20 October 2010

Accepted 6 January 2011

Available online $\mathrm{xxxx}$

\section{Keywords:}

TEM

Reflection seismic

Co-interpretation

Geological mapping

\begin{abstract}
A B S T R A C T
Airborne electromagnetic methods (AEM) are used extensively in groundwater investigations, often in combination with high-resolution seismic data. Despite the frequent use of this mapping strategy, only a few cases are found in the literature. In this study, comparisons and interpretations were made based on AEM (SkyTEM) and high-resolution seismic data from an area covering $10 \mathrm{~km}^{2}$ in the western part of Denmark. As support for the interpretations, an exploration well was drilled to provide lithological and logging information in the form of resistivity and vertical seismic profiling. Based on the resistivity log, synthetic SkyTEM responses were calculated with a varying number of gate-times in order to illustrate the effect of the noise-level. At the exploration well geophysical data were compared to the lithological log; in general there is good agreement. The same tendency was recognised when SkyTEM results from the area were superposed onto seismic sections. Comprehensive geological knowledge is necessary in order to introduce layer boundaries from one method interactively in the data handling of the other. However, in cases where resistivity transitions are positively correlated to reflections, SkyTEM data supports the interpretation of weak reflections, and can also support the correlation of reflections both internally and between seismic lines. Besides contributing lithological information, the AEM survey provides gross three-dimensional structural information, whereas seismic data contributes with more detailed structural information in two dimensions.
\end{abstract}

(ㄷ) 2011 Elsevier Ltd. All rights reserved.

\section{Introduction}

Geophysical data often form the basis for development of geological models, especially in heterogeneous environments where point observations from wells are inadequate to map complex geology. While geoelectrical methods typically only resolve the topmost part of the geological setting, TEM and high-resolution seismic data focus on the geological setting to a depth in the order of 200-300 m.

The SkyTEM method (Sørensen and Auken, 2004) has good resolution capability of the near-surface geology, and dense SkyTEM data sets have been collected to provide lithological and threedimensional structural information of geological settings. Often, SkyTEM data have been used to place the more expensive high-resolution seismic profiles that contribute detailed structural information along 2-D lines. The combined use of the two methods has proven to be a very cost-effective way to conduct geological mapping, however, only little attention has yet been paid to develop methodologies for combined interpretation of the two methods.

\footnotetext{
* Corresponding author at: University of Aarhus, Department of Earth Sciences, Denmark.

E-mail address: annesophie.hoyer@geo.au.dk (A.-S. Høyer).
}

This paper is a methodological paper where we investigate perspectives and pitfalls in the combined use of the TEM and high-resolution seismic methods when applied to geological mapping. This will be based on results obtained from a case study in which both SkyTEM and seismic data have been acquired in a heterogeneous geological setting.

\section{Methods}

\subsection{The SkyTEM method}

The TEM (transient electromagnetic) method was originally developed in the 1960s and 1970s for mineral exploration (Fountain, 1998). One of the first studies focusing on groundwater mapping using the TEM method was published by Fitterman and Stewart (1986). Since then the method has been applied to hydrogeological mapping worldwide in a wide variety of geological settings (Mills et al., 1988; Meju et al., 1999; Yang et al., 1999; Buselli and Lu, 2001; Auken et al., 2003; Danielsen et al., 2007; D'Ozouville et al., 2008). Since 2000 a number of large scale surveys have been conducted in Australia in the Murray-Darling river basin (McEwan and Jolly, 2006; Munday et al., 2007) looking at problems of saline groundwater, in Botswana where the entire Okavango delta (Podgorski et al., 2010) was mapped for a spatial delineation of the sal- 
ine and fresh water, and also in Denmark more than $11.000 \mathrm{~km}^{2}$, corresponding to a quarter of the country, has been mapped since the mid 1990s (Møller et al., 2009).

The SkyTEM method has gone through continuous developments and improvements. The improvements focus on three aspects: (1) technical development (Danielsen et al., 2003; Sørensen and Auken, 2004), (2) improvement of software and data handling (Auken et al., 2005, 2009; Viezzoli et al., 2008a,b), and (3) advances in geological interpretation (Jørgensen et al., 2003b, 2005).

With the development of an airborne transient electromagnetic method ('the SkyTEM system', Sørensen and Auken, 2004) it became cost-effective to collect dense data grids over large survey areas. Thanks to the continuous data collection, recognition of galvanically coupled responses (e.g. pipes and grounded fences) has become achievable. In single-site surveys it is normally impossible to recognise this type of coupling since their decay curves are similar to those of undisturbed earth responses (Sørensen et al., 2001). Another advantage of the dense surveys is the vista for application of inversion algorithms that can improve the resolution of weakly resolved parameters (Auken and Christiansen, 2004; Auken et al., 2005, 2008; Viezzoli et al., 2008a) and hereby improve geological understanding in areas with poorer data quality.

Being a transient electromagnetic method, SkyTEM functions by transmitting a direct current in a transmitter loop, carried as an external sling load below the helicopter. The transmitted current creates a primary magnetic field which, when turned off, induces an eddy current system in the ground. The subsurface currents diffuse obliquely downwards and decay as a consequence of the ohmic resistance in the ground. The system induces a secondary magnetic field, whose time-derivative is measured in the receiver coil. Since the magnitude and decay rate of the response are related to the conductivity and distribution of geological layers, the method provides information of the subsurface resistivity distribution.

The decay of induced currents is slower in a conductive than in a resistive medium, which is the reason for the superior resolution of conductive layers, especially at great depths when overlain by higher resistivities (Danielsen et al., 2003). High resistivities are not precisely determined but only recognised as 'high resistivities' when using the TEM method. Furthermore, certain geological settings give rise to data responses where resolution of exact thicknesses and/or resistivities is impossible due to equivalence problems.

Due to the diffusive nature of the method it has a decreasing resolution capability with depth. As a rule of thumb layers have to be more than $20-50 \mathrm{~m}$ thick to be resolved at $100 \mathrm{~m}$ depth (Jørgensen et al., 2005). Spatial resolution decreases considerably with depth and the ability to resolve 3D structures is therefore significantly decreased with depth (Danielsen et al., 2003).

Ultimately the resolution of shallow layers is mainly dependent on the time for the first unbiased data, while the depth penetration depends on the signal-to-noise ratio at late measuring times. The alternating application of low- and high-moments in the SkyTEM system secures a resolution and depth penetration comparable to groundbased-systems like the Protem 47 (Geonics, Inc.). Thus, when using the 'super low moment' of the SkyTEM system, it is possible to obtain unbiased data from about 10 to $12 \mu \mathrm{s}$ after transmitter-current turn-off, achieving a resolution capability comparable to the conventional $40 \times 40 \mathrm{~m}^{2}$ ground-based system (Auken et al., 2009). On the other hand, using the 'high moment' it is possible to achieve depth penetration corresponding to the $\mathrm{Hi}$ TEM system (Jørgensen et al., 2005).

\subsection{The vibro-seismic method}

Seismic studies have traditionally been associated with the oil industry, where the method is well-known as an effective way of collecting large amounts of high-resolution, high-quality marine data. Unfortunately, collection of seismic data is much more troublesome on land, and it is also difficult to achieve the same data quality as can be obtained in marine studies. Some of the factors responsible for the poorer data quality on land are the influence of source-generated noise (e.g. direct, surface, and airwaves) and the effects from near-surface, low velocity layers above the groundwater table (e.g. attenuation of high frequencies and variable static effects).

Due to the high resolution capacity of the method it has been widely used for hydrogeological and environmental purposes since the 1980s (Jongerius and Helbig, 1988; Büker et al., 1998; Steeples et al., 1995; Pugin et al., 1999; Jørgensen et al., 2003a), and the method is steadily undergoing refinements in order to enhance efficiency and data quality. In this process various systems and different setups have been studied (Miller et al., 1986, 1992; Steeples and Miller, 1990; van der Veen et al., 2000), and comprehensive evolution of data handling and processing has taken place (Steeples and Miller, 1990; Büker et al., 1998; Pugin and Pullan, 2000).

A breakthrough in the optimisation of seismic data collection strategy occurred with the development of land streamers (van der Veen and Green, 1998; van der Veen et al., 2001; VangkildePedersen et al., 2003, 2006). The combined use of vibratory sources and land streamers has in particular enhanced the efficiency of the method without compromising the quality of data (VangkildePedersen et al., 2003, 2006). As an example, more than $1400 \mathrm{~km}$ of seismic profiling (Møller et al., 2009) have been collected in Denmark since the implementation of land streamers.

The seismic method makes use of the elastic properties of subsurface materials. In vibro-seismics the source of seismic waves is a vibrator emitting a pulse of controlled seismic energy into the ground. Energy, in the form of seismic waves, travels spherically away from the source, both through the air, along the surface, and underground. In the subsurface the waves are refracted and reflected when they reach boundaries with marked contrasts in seismic velocity and density. Typically the seismic energy is collected by land streamer geophones towed by the vibrator. During processing the objective is to enhance the signal-to-noise ratio in the final reflection seismic profile by removing everything except the reflected energy. In the processing, data are sorted in CMP (common midpoint) gathers and stacked, leading to a seismic profile with two-way-travel-time on the vertical axis.

For co-interpretation of seismic profiles with other geophysical or geological data two-way-times have to be translated into real depths. The velocities chosen for depth conversion are therefore a crucial factor in the co-interpretation. The most accurate velocities are achieved when vertical seismic profiles are carried out (Jørgensen et al., 2003a). However, the point observations obtained from vertical seismic profiling can be difficult to extrapolate in complex geological environments and will always entail a factor of uncertainty.

The target depth of investigation is indirectly chosen when selecting the geophone-offset and the frequency spectrum of the source. Hence, large offsets and low frequencies result in deeper target-depths than smaller offsets and higher frequencies. By emitting a rather broad spectrum of frequencies with the vibrator, the objective is to resolve near-surface structures while maintaining a reasonable depth of penetration. According to the Rayleigh criterion, bed thicknesses have to correspond to at least one-quarter wavelength to be resolved (Steeples and Miller, 1990). However, when having noisy field data, experience shows that thicknesses have to correspond to a half pulse-length to be resolved with certainty. For instance with a dominant frequency of $150 \mathrm{~Hz}$ and a seismic velocity of $1800 \mathrm{~m} / \mathrm{s}$ the vertical resolution is approximately $6 \mathrm{~m}$. Hence, in typical geological settings with higher seismic velocities in deeper layers the vertical resolution deteriorates 
slightly with depth. The lateral resolution is described by the first Fresnel zone (Steeples and Miller, 1990). With constant seismic velocity and frequency corresponding to those mentioned above, the Fresnel zone is $16 \mathrm{~m}$ and $33 \mathrm{~m}$ respectively at two-way travel times of $50 \mathrm{~ms}$ and $200 \mathrm{~ms}$. Lateral resolution consequently experiences the most significant decrease with depth.

When observing seismic profiles it is important to be aware of possible artifacts. Side swipes are a significant artifact originating from reflectors present outside the two-dimensional extent of the seismic line. While this is an issue on all seismic sections in heterogeneous environments, there are also some artifacts connected to the selected processing strategy. Migration is commonly not performed on land data since the high noise level can lead to unwanted noise produced by the migration process. When interpreting it is important to bear in mind that unmigrated seismic sections show too small gradients of inclined structures and that diffraction hyperbolas can be present.

Besides being influenced by conditions like weather and traffic, seismic data quality is mostly dependent on the characteristics of near-surface sediments. Experience shows that data quality is best in areas with compacted, water-saturated clayey sediments rather than unsaturated sandy material in the near-surface.

\section{Previous work on combined use of seismics and electromagnetics in hydrogeological mapping}

Despite the fact that both electromagnetic surveys and reflection seismic profiling have been extensively used in hydrogeological mapping, co-interpretation of the methods has, until recently, been a relatively unexplored discipline. One of the only studies from last century was provided by Duran (1987). Riverine seismic and frequency-domain EM surveys were carried out at the Delaware River (New Jersey, US) in order to resolve the hydraulic regime. By comparing the two datasets it was found that the conductivity data provided substantial support for the seismic interpretation - especially in areas with poor seismic data quality. A comparable study with riverine boomer seismics and EM data was successfully conducted by Butler et al. (2004) at the Saint John River in Canada.

Based on geophysical data from a coastal aquifer in the Nitzanim area of Israel, Shtivelman and Goldman (2000) published the first results of an integrated interpretation of reflection seismics and transient electromagnetic data. In the final interpretation, knowledge from seismic data was used to include an additional layer in the TEM inversion (Fig. 1), which, according to the authors, significantly improved the geological interpretation. In the same period another integrated TEM and seismic study was carried out in Italy (Deidda et al., 2000) with the objective to study salt water intrusion in a coastal area.

The vast majority of investigations using combined seismic and EM methods have been performed in Northern Europe in connection with a comprehensive study of buried valleys as potential groundwater reservoirs. The first results of these investigations were published by Auken et al. (2003), Gabriel et al. (2003), and Jørgensen et al. (2003a,c). The studies revealed that the geological interpretation was substantially improved by combining structural information from the seismic profiling with predominantly lithological information derived from electromagnetic data. An advantageous mapping strategy where the results of large-scale TEM surveys were used to select the optimal location for the more expensive seismic profiles was proposed by Jørgensen et al. (2003a).

A transnational project with the objective to systematically study buried valleys of the North Sea Region was initiated in 2004 ('the BurVal Project', BurVal Working Group, 2006). Six pilot
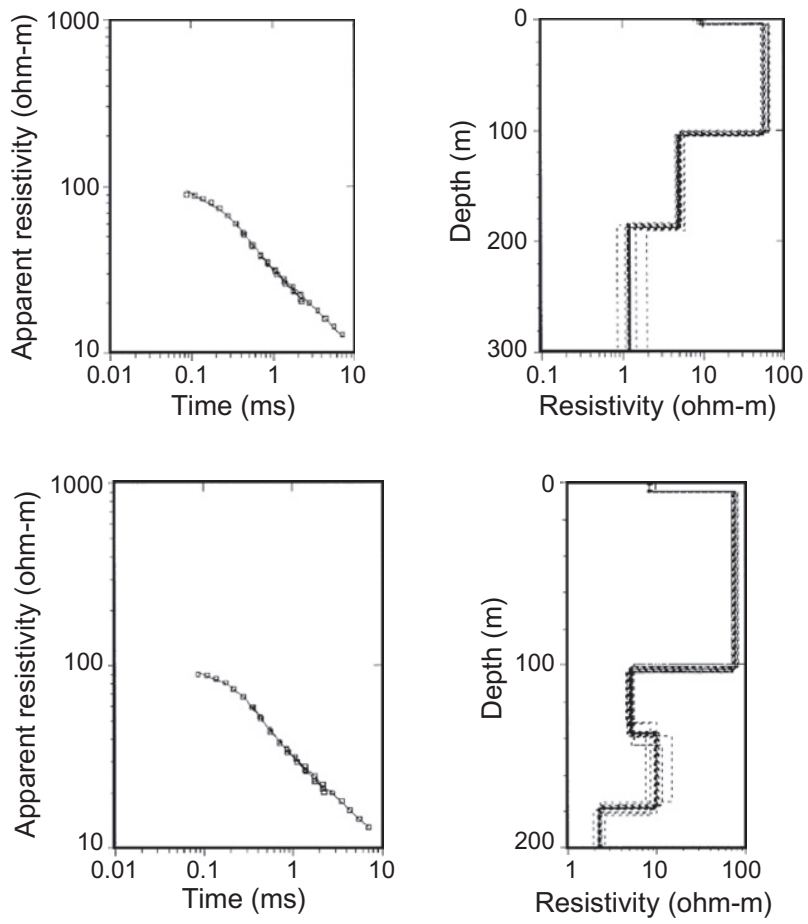

Fig. 1. Modified from Shtivelman and Goldman (2000). 1-D interpretations of TEM data without "a priori" information from seismics (above) and with "a priori" information (below).

project areas were intensively investigated with a wide range of methodologies - including reflection seismic profiling and electromagnetic surveying in both time- and frequency-domain. An overview of the results was published by the BurVal Working Group (2006, 2009). They concluded that the geological interpretation was supported, by the combined use of at least two geophysical methods - and especially the combined use of airborne electromagnetic surveying and reflection seismic profiling proved to be very effective. Further discussion of the importance of data density was given by Jørgensen and Sandersen (2009), while the potential of integrated data sets as a tool for 3D geological modelling was discussed by Rumpel et al. (2009) and Bosch et al. (2009).

Until now the co-interpretation has predominantly been performed by pure comparison between data results. However, in the study by Shtivelman and Goldman (2000) seismic "a priori" information was used in the TEM interpretation. In other studies seismic sections have been depth-converted on the basis of depths obtained from the TEM results (Jørgensen et al., 2003a; Auken et al., 2003).

\section{Geological setting}

The study area covers $10 \times 10 \mathrm{~km}^{2}$ and is located by the town Ølgod in the western part of Jutland, Denmark (Fig. 2). In this part of the country, well-protected groundwater reservoirs are often found in Miocene sand deposits (Rasmussen et al., 2004), while impermeable Paleogene clays typically form the bottom of the aquifers. The Quaternary and Neogene deposits are therefore of great interest as groundwater reservoirs.

The Selandian and Eocene successions were deposited in a marine environment and consist of sticky clays and marls with a total thickness of around $100 \mathrm{~m}$ (Larsen and Kronborg, 1994). Due to its location on top of the Ringkøbing-Fyn High the area was partly exposed during the Oligocene, preventing deposition until late in this period (Binderup et al., 2006). In the Miocene the area was in a 

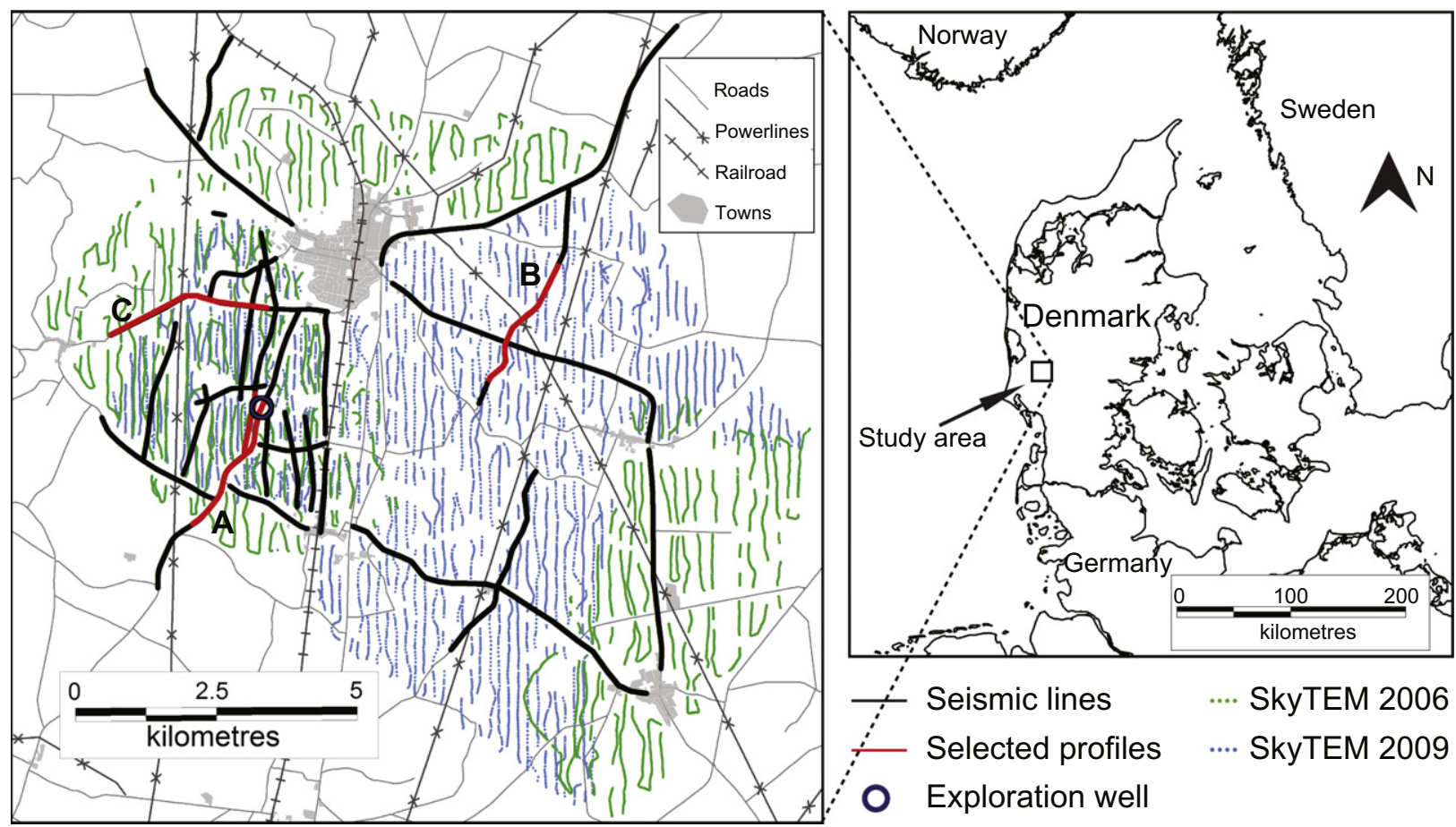

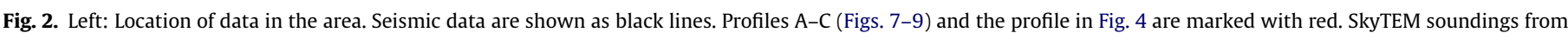

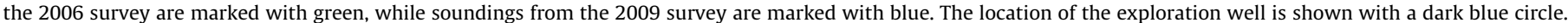
Right: Location map.

coastal environment with alternating sedimentation of clayey, silty and sandy material of marine, deltaic and fluvial origin (Rasmussen et al., 2007). Observed thicknesses of Late Oligocene and Miocene deposits amount to around $200 \mathrm{~m}$ (Larsen and Kronborg, 1994). Pliocene deposits are not found onshore in Denmark, and some researchers assume that around $400 \mathrm{~m}$ of Neogene sediments were removed during the Quaternary as a consequence of glacial erosion (Binderup et al., 2006).

Evidence of three glacial periods (Menapian, Elsterian and Saalian) and intervening interglacials are found in the area (Andersen, 1965; Larsen and Kronborg, 1994). Glaciers from the last Danish ice age (Weichsel) did not reach western Jutland. The landscape in the area was formed during the Saale ice age and was later subjected to slumping processes during the Weichsel, giving rise to the slightly undulating landscape visible today.

\section{Data collection and processing}

\subsection{SkyTEM data collection and processing}

SkyTEM surveying has been performed in the study area, first with the collection of 174 line kilometres in 2006 and then with 418 line kilometres in 2009 (Fig. 2). Parts of the survey areas were overlapping. The data density varies from a line spacing of $125 \mathrm{~m}$ in parts of the newer data set to $270 \mathrm{~m}$ in the older data set. In the 2009 survey, the first unbiased gate is in $12 \mu$ s from begin of ramp and the last usable gate is around 5-6 ms (Fig. 3). Corresponding values for the 2006 survey are $18 \mu \mathrm{s}$ and $2-3 \mathrm{~ms}$, respectively.

In order to be able to conduct a joint inversion, processing of the two data sets was performed using the same approach. Initially navigation data (altitude, tilt of the frame and GPS position) were processed both automatically and manually. Hereafter disturbed data due to galvanic coupling were removed manually from the voltage data. Data were filtered by lateral average filters, narrow at early times and wider at late times. In this way, the ability to re- solve the lateral variability in near-surface geology is utilized, while the depth penetration is enhanced by further improving the signal-to-noise ratio at depth (Auken et al., 2009).

The inversion was performed using a 'smooth model' composed of 19 layers having pre-defined thicknesses and resistivities that may vary within a certain interval (Fig. 3). The 19 layer model compromises sufficient smoothness and computational speed of the forward and inverse problem. The model provides smooth vertical resistivity variations due to the presence of vertical constraints. This model setup was chosen because it was more effective in resolving the heterogeneous geology than inversions based on models with only few layers. The final inversion was performed using the spatially constrained inversion technique (Viezzoli et al., 2008b).

When SkyTEM soundings and seismic lines are closely spaced, the two sets of data can successfully be represented together by interpolating 1D TEM models onto the seismic line (Fig. 4). However, when there are considerable distances between the two data sets, the most realistic resistivity values along the seismic section are obtained by studying interpolated TEM grids. In the following, TEM results along the roads, where SkyTEM data generally are discarded due to coupling noise, are displayed as cross sections through a number of $5 \mathrm{~m}$ interval resistivity grids (Figs. 7-9). An estimated penetration depth is illustrated by the use of less saturated colours in areas with only minor sensitivity of the TEM method. The penetration depths are partly estimated on basis of the time for the last gate-times in the surrounding TEM data - and partly on basis of the resulting resistivity models (Christiansen and Auken, 2010). Given that the method has most sensitivity towards low resistivities, the penetration is best in areas with a deep lying conductor, compared to areas where the presence of thick units of shallow low-resistive layers in some cases can prevent resolution of underlying layers. In order to get a feel for the interpolation distances, the presence of 1D TEM models within $200 \mathrm{~m}$ of the profile is marked by black bars above the profiles (Figs. 7-9). 

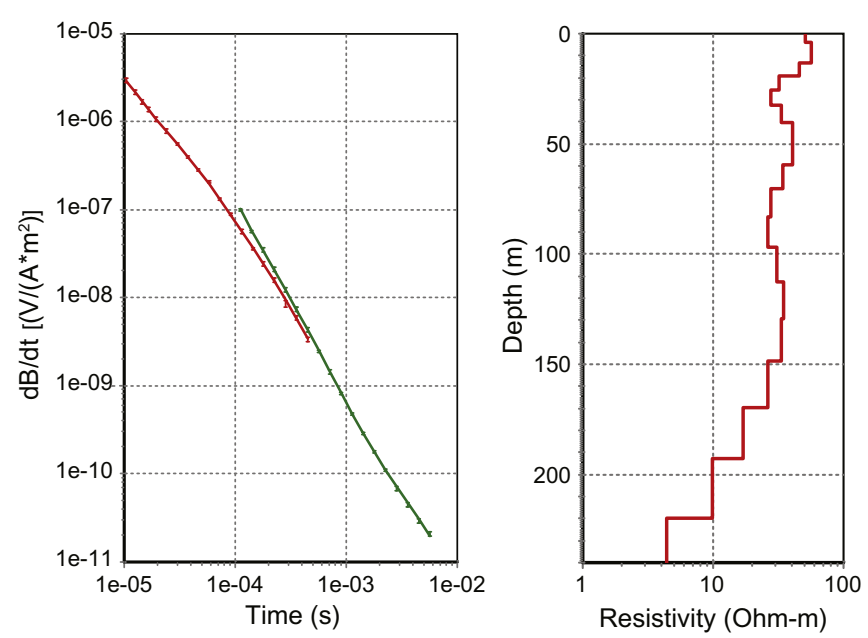

Fig. 3. Representative sounding (left) from the 2009 survey. The red curve shows the high moment, while the green curve shows the low moment. The associated model is seen at the right side. Data residual for the model amounts to 0.57 .

\subsection{Seismic data collection and processing}

In the survey area $77 \mathrm{~km}$ of seismic profiling was collected during 2008 and 2009. The majority $(60 \mathrm{~km})$ of lines were collected along roads, while the rest were collected on cultivated fields. A hydraulic vibrator emitting a frequency range increasing linearly from 10 to $300 \mathrm{~Hz}$ was used as the seismic source. Four vertical stacks were measured at each vibration point. The separation between vibration points was $10 \mathrm{~m}$ measured with a distance-counter mounted on the vibrator. The road-sections were collected with an end-on configuration where a land-streamer was towed by the vibrator. Due to practical difficulties the land-streamer setup was not used on the fields; these data were collected using a conventional spread split configuration. All the seismic profiles were collected using 72 geophones. The internal separation-distance on the land-streamer was $2.5 \mathrm{~m}$, whereas it was $5 \mathrm{~m}$ on the conventional cables. Inline near-geophone offsets were $20 \mathrm{~m}$ and $0 \mathrm{~m}$, while offline offsets corresponded to $0 \mathrm{~m}$ and $1 \mathrm{~m}$, respectively.

The main steps in the processing consisted of importing of field geometry from nav-files generated from GPS-positions and independent measurements of distances along lines, trace editing and muting, bandpass filtering, velocity analysis, application of residual statics, normal moveout corrections, CMP stacking, and depth conversion. Unfortunately data were too noisy to obtain good results by deconvolution and migration. Depth conversion was performed on the basis of the results of a vertical seismic profile in the area (Section 6.1).

Overall seismic data quality is good considering that it is landbased data. However, the field-profiles (example in Fig. 4) show more ringing than profiles measured on roads (Figs. 7-9). This is believed to stem from poorer acoustic ground-coupling on the fields entailing loss of high frequencies and leading to a narrow frequency spectrum that enhances ringing.

\subsection{Exploration well}

To support the geological interpretation of the seismic and SkyTEM data an exploration well was placed in the central part of the survey area close to one of the seismic lines. Detailed lithological analysis, together with a vertical seismic profile and a number of different logs, including resistivity, were carried out (Fig. 5).

The vertical seismic profile was performed using a sledgehammer as the energy source and data was recorded using a borehole streamer with 12 hydrophones at $2 \mathrm{~m}$ intervals. Seismic interval velocities were calculated from first break arrivals. Due to limited resolution, only four interval velocities were derived - each interval containing several geological layers.

Resistivities were measured with a normal log with four electrode separations $\left(8-64^{\prime \prime}\right)$. In order to obtain the most reliable formation resistivities the longest resistivity $\log \left(64^{\prime \prime}\right)$ was used. However, since this log is specialized in measuring resistivities in the range $20-200 \Omega-m$, readings from the short resistivity $\log \left(8^{\prime \prime}\right)$ were used below $-175 \mathrm{~m}$ in order to resolve the low resistivities at these elevations.

\section{Results}

\subsection{Exploration well}

The data results from the exploration well, together with a segment of the seismic profile located by the well, are shown in Fig. 5. It is evident from the lithological log that the sediments below elevation $-100 \mathrm{~m}$ mainly consist of fine-grained material, apart from

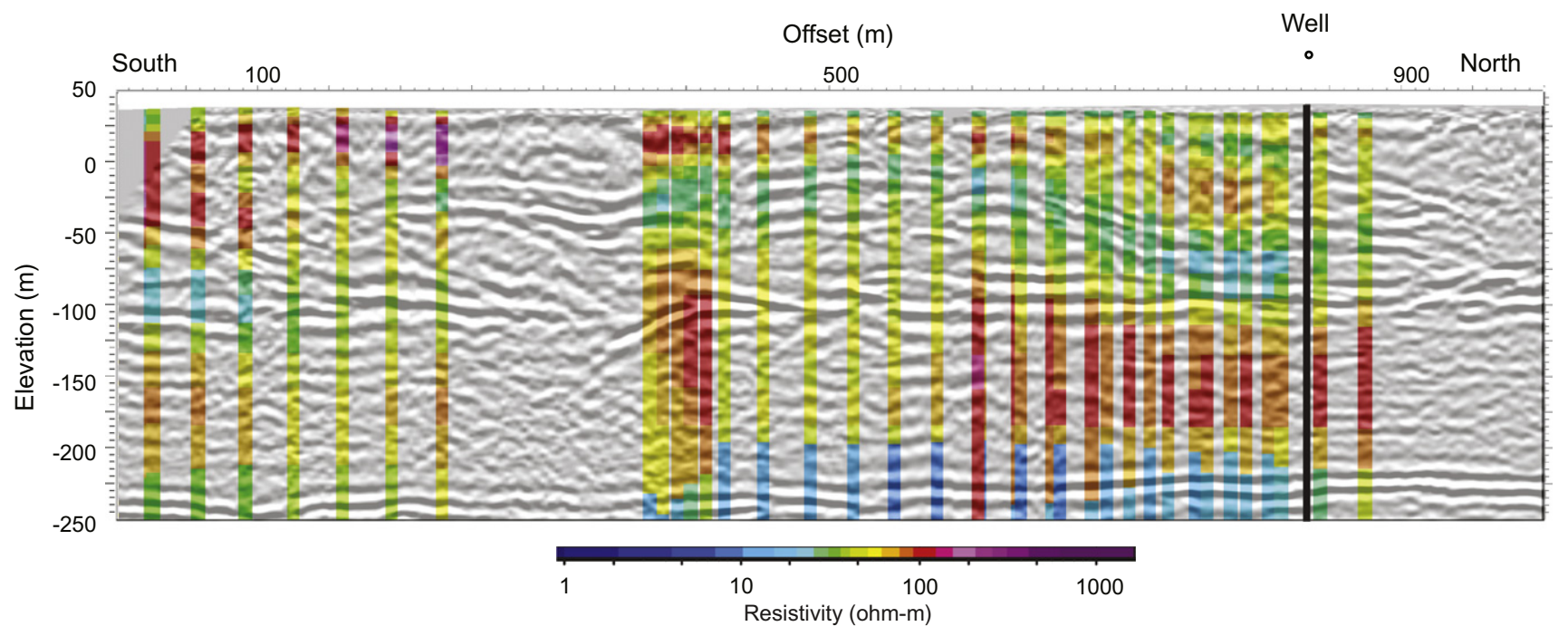

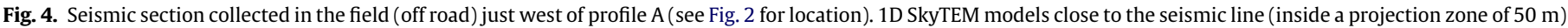

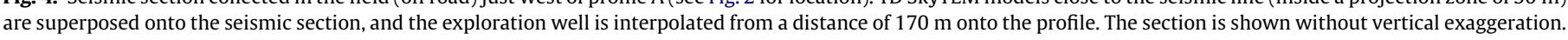


a $40 \mathrm{~m}$ thick unit consisting of silt and sand. The sediments below $-100 \mathrm{~m}$ are of Paleogene and Neogene age (Dybkjær, 2010), and the seismic velocity was found to be $1840 \mathrm{~m} / \mathrm{s}$ by the vertical seismic profiling. This corresponds closely to velocities that have previously been recognised in Neogene and Paleogene successions (1750 m/s according to Lykke-Andersen and Tychsen (1977)). From the bottom of the well to $-120 \mathrm{~m}$ the resistivity log indicates a gradual increase from $2 \Omega$-m to $150 \Omega$-m, after which the curve drops rapidly around $-100 \mathrm{~m}$. The seismic section in this interval shows two clear reflections at the bottom (coincident with a sharp resistivity boundary at $-225 \mathrm{~m}$ ), overlain by many horizontal reflections with distinct amplitudes and short wavelengths. It appears that some of the reflections (e.g. at $-190 \mathrm{~m}$ ) are not coincident with layer boundaries recognised on the lithological log, just like some of them (e.g. at $-160 \mathrm{~m}$ ) are not recognised on the resistivity $\log$.

In the interval $-100 \mathrm{~m}$ to $-40 \mathrm{~m}$ the sediments are primarily clay-rich, interpreted from borehole samples as till and meltwater or glacio-lacustrine clay. A mean seismic velocity of $1920 \mathrm{~m} / \mathrm{s}$ is measured by the vertical seismic profiling for these sediments. This mean value corresponds to the typical seismic velocities of $2150 \pm 100 \mathrm{~m} / \mathrm{s}$ and $1750 \pm 100 \mathrm{~m} / \mathrm{s}$ for tills and meltwater/glacio-lacustrine sediments respectively (Jørgensen et al., 2003a). The resistivity log shows some significant fluctuations connected to lithological variations in the succession. The clay successions show relatively low resistivities, while the till successions show higher values, in accordance with the expected response for these sediment types (Jørgensen et al., 2003b). The interval is enclosed by marked reflections coincident with the strongest resistivity fluctuations.

From $-40 \mathrm{~m}$ to $0 \mathrm{~m}$ the sediments are predominantly sandy showing quite constant resistivity values around $100 \Omega-\mathrm{m}$, whereas the topmost sequence from $0 \mathrm{~m}$ to $40 \mathrm{~m}$ consists of many individual layers with differing grain-sizes, resulting in a variable resistivity pattern. Apart from an unsaturated zone showing low seismic velocity $(1070 \mathrm{~m} / \mathrm{s})$ in the topmost $10 \mathrm{~m}$, these layers obtained an average seismic velocity of $1750 \mathrm{~m} / \mathrm{s}$. The sandy interval appears transparent on the seismic section, whereas the alternating layer sequence in the near-surface appears more reflective. However, the individual reflections are hard to follow as a result of the lower CDP (common depth point) fold in the near-surface layers.

Due to the lateral variability, we decided to perform a depthconversion based on just two velocity intervals in order to avoid making a misleading interpretation of data. All the seismic sections were therefore depth-converted with a velocity of $1070 \mathrm{~m} / \mathrm{s}$ in the topmost $10 \mathrm{~m}$ and an average velocity of $1840 \mathrm{~m} / \mathrm{s}$ in the remaining part of the sections.

\subsection{Synthetic SkyTEM responses}

Unfortunately there are no SkyTEM soundings at the well site due to coupling. In order to study the SkyTEM data response and compare this to the seismic and lithological data, two synthetic SkyTEM responses were made to illustrate typical SkyTEM soundings from the 2006 and 2009 survey, respectively (Fig. 5). Values from the resistivity log were used as the model for the inversions. The difference between the two models stems from different times for the last included data point; one model simulates the response with usable gate-times until $1.8 \mathrm{~ms}$, which is a typical cut-off value for soundings from the 2006 survey, whereas the other model simulates a sounding from the 2009 survey with cut-off at $5.6 \mathrm{~ms}$.

Model responses of the two inversions are very similar in the topmost $140 \mathrm{~m}$, while at greater depth the curves show completely different trends. When data are present until $5.6 \mathrm{~ms}$, the model detects the low resistivity layer at depth. In the other situation, with fewer usable gate times, the deeper part cannot be resolved, leading to a model with far too high resistivity values at depth.

Since the descending tendency at late times is recognised in the sounding curves from the area, a few data points more or less can be crucial to resolve the lower part of this geological sequence. When applying spatially constrained inversion, deep parts of models in areas without late-time data will be determined by the vertical and lateral constraints, and the effective resolution in depth can hereby be enhanced.

\subsection{SkyTEM}

The results of the SkyTEM survey are outlined in a 3D-view with one horizontal and two vertical sections showing the resistivities in the study area (Fig. 6). As seen on the horizontal section, a distinct difference is recognised between the data results from the eastern and western parts at great depths. Hence, data from the eastern part consistently indicate the existence of a good conductor, whereas the western data show a more variable resistivity pattern, with only sporadic evidence of a good conductor at depth. The good conductor is generally dipping towards the west from levels around $-145 \mathrm{~m}$ in the east to levels that exceed the exploration depth in the west. The shallow data, on the other hand, indicate a heterogeneous resistivity pattern in the entire area. This is illustrated on the two vertical sections in Fig. 6 where low-resistive layers, interpreted as clayey successions, fluctuate up and down on both sections.

\subsection{Vibro-seismics}

Selected seismic sections are presented in Figs. 4 and 7-9. In general the seismic sections show a horizontally-layered sequence below elevations of approximately $-100 \mathrm{~m}$. Above this, the area is characterized by a complex setting with individual structures of $100-400 \mathrm{~m}$ in width and with thicknesses of up to $100 \mathrm{~m}$. Due to the limited lateral extent of these structures, individual reflections are almost impossible to follow between seismic lines, despite the relatively dense coverage of seismic profiles.

\subsection{Comparison of results from SkyTEM and seismics}

Comparison of SkyTEM and seismic data is illustrated on three vertical profiles (profiles A-C in Figs. 7-9) that follow selected seismic sections. Profile A (Fig. 7) was collected in the western part of the study area (Fig. 2) where resistivity values fluctuate laterally at great depths (Section 6.3). This fluctuation is recognisable on the profile because the resistivities at depth change from high $(>100 \Omega-\mathrm{m}$ ) in the central part (offset $1700-2800 \mathrm{~m}$ ) to low

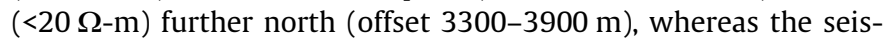
mic section in this elevation interval reflects a horizontally-layered sequence. The shallow low resistive $(<20 \Omega-\mathrm{m})$ unit in the southern part of the profile is shielding the resolution of the deeper section. Based on the well information and seismic data, it is thus likely that the layer that produces the good conductor is present in the entire area even though it is not seen on the TEM data. Above the estimated penetration depth, lateral resistivity variations are more steady, overall being consistent with many of the main structures seen on the seismic section. The most striking correlation is the way in which the low-resistive unit drapes the significant reflection sloping northward from offset $1400 \mathrm{~m}$ to $3200 \mathrm{~m}$. In the near-surface, weak reflections constitute the lower boundary of an area with significantly higher resistivities than the surroundings. This leads to the interpretation of horizons (green and blue) that would be difficult to interpret based solely on seismic data.

Profile B (Fig. 8) is situated in the eastern part of the study area (Fig. 2) where the deep-lying good conductor is consistently indi- 


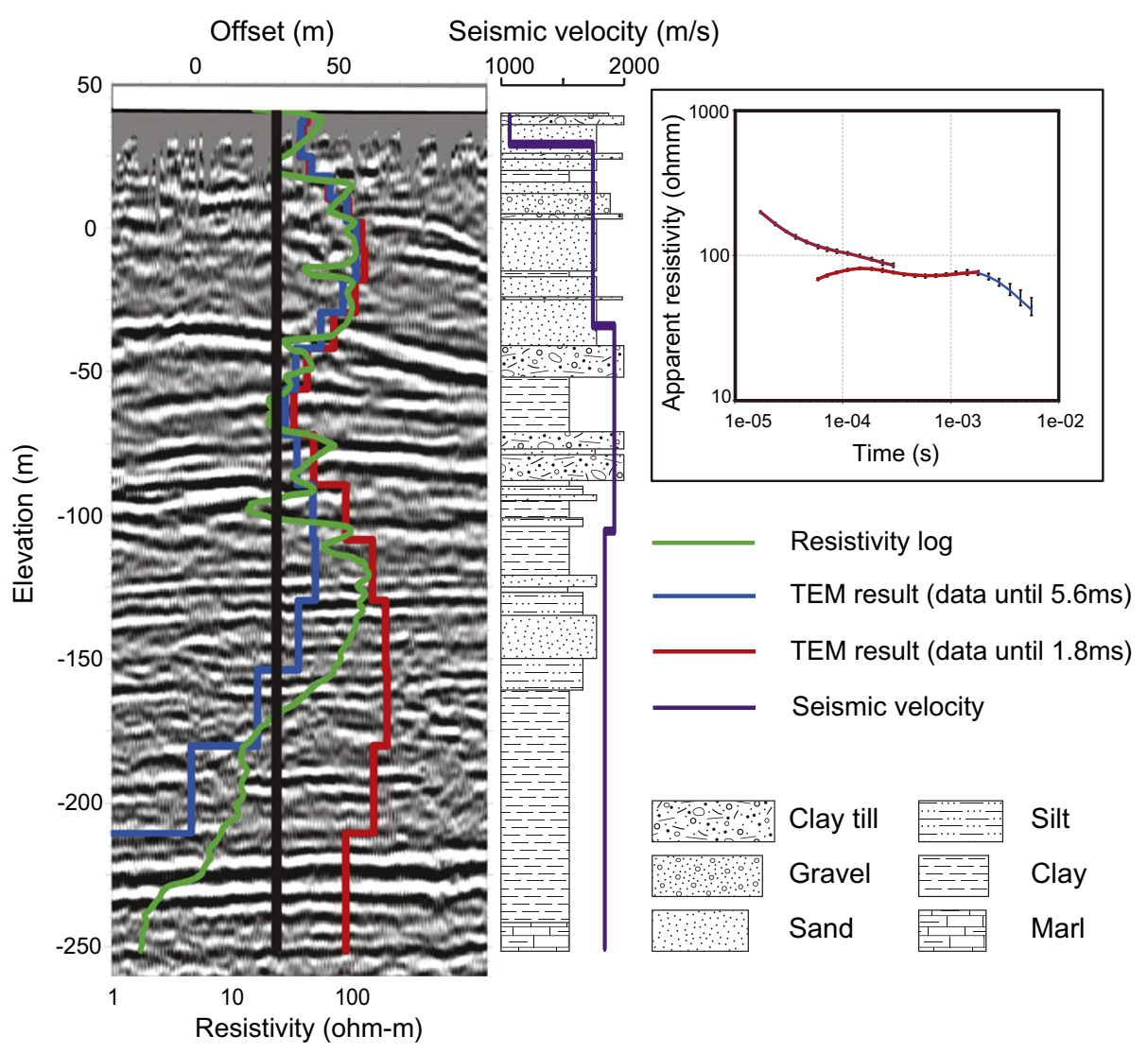

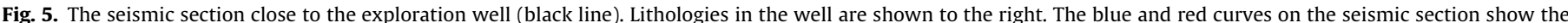

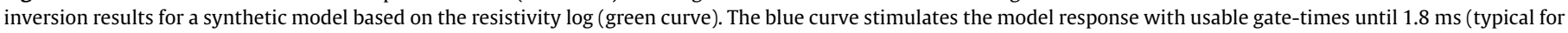

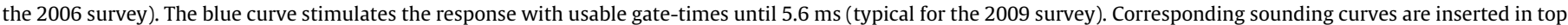
right. The seismic section is shown without vertical exaggeration.

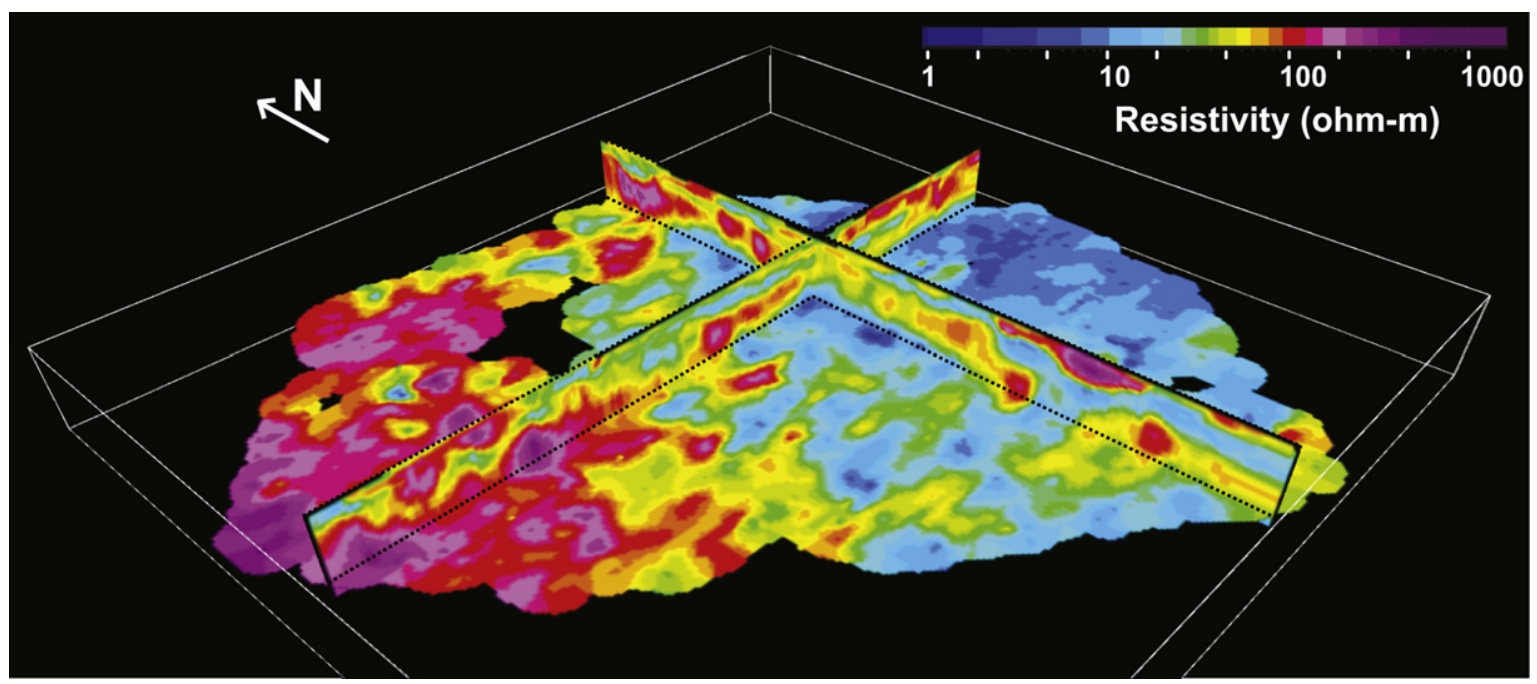

Fig. 6. Slices through the SkyTEM resistivity grid in the study area. Horizontal $(-175 \mathrm{~m})$ and two vertical slices. Vertical exaggeration: $\times 5$.

cated by SkyTEM data. The overlying interval from $-150 \mathrm{~m}$ to $-25 \mathrm{~m}$ stands out on the TEM section and can also be recognised on the seismic profile. The interval is almost constant in thickness except for a depression from offset $1100 \mathrm{~m}$ to $1450 \mathrm{~m}$ - interpreted as a narrow buried valley. The depth interval is bounded by clear reflections on the seismic section and by abrupt transitions in resistivities on the TEM grid where the transitions occur across only a few layers in the models. However, many distinct reflections are recognised around the lower boundary of the interval, and the TEM results are useful in delineating the lower boundary of the unit (red horizon). Resistivities in the interval are high $(>70 \Omega$ $\mathrm{m})$, apart from a smaller area from offset $1400 \mathrm{~m}$ to $1600 \mathrm{~m}$ that shows more moderate values ( 30-40 $\Omega-\mathrm{m}$ ). The convergence between the location of this resistivity low and an area with ambiguous seismic reflections could raise doubt about the seismic interpretation of the extent of the depression. The low moment 

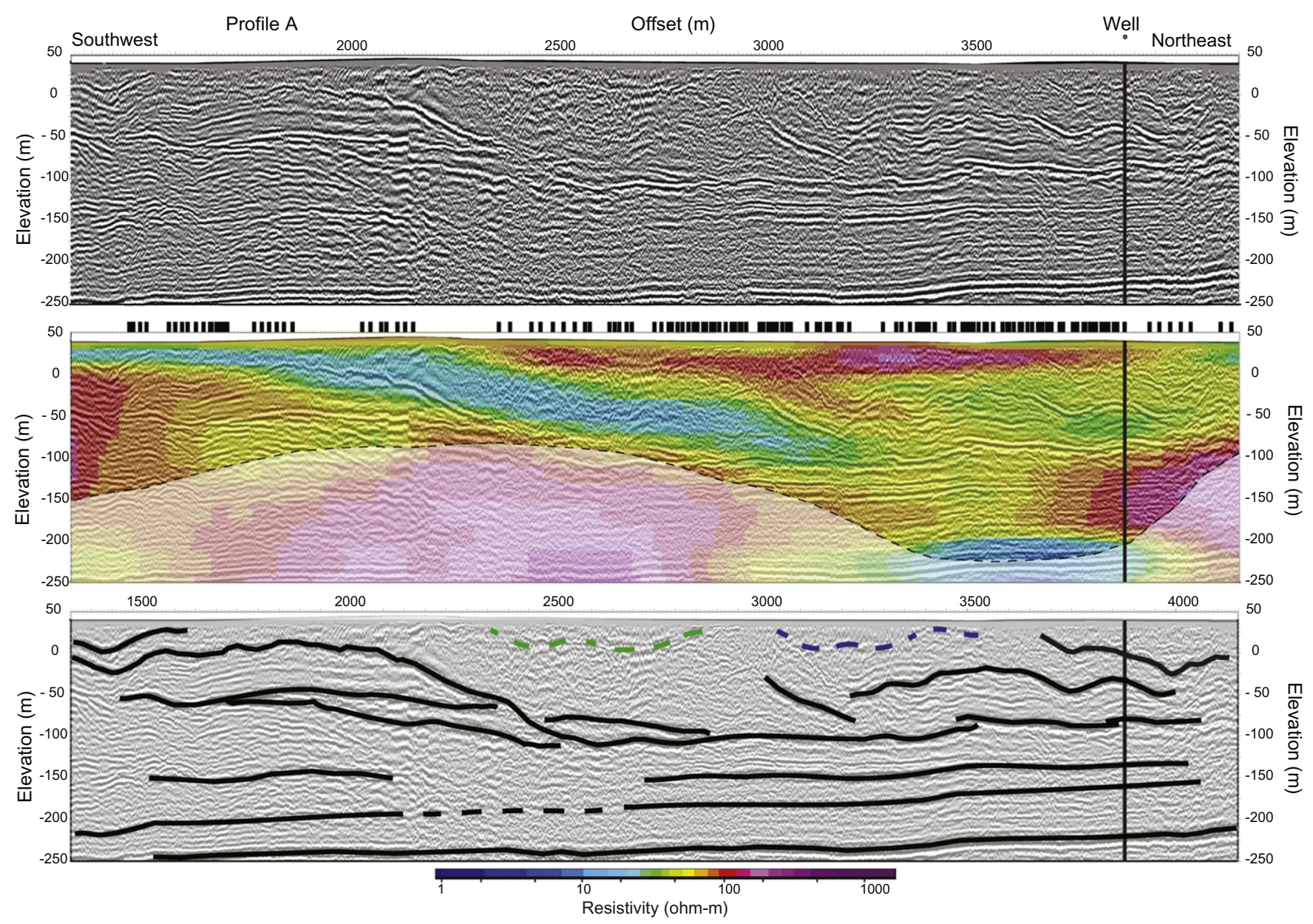

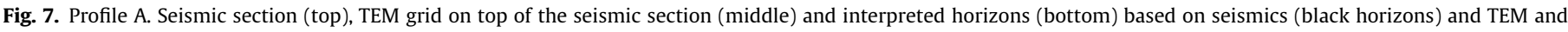

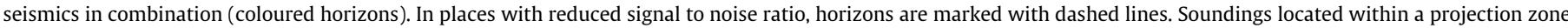

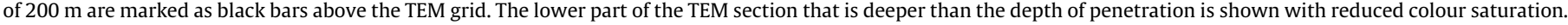
Location of the profile is shown in Fig. 2. Vertical exaggeration: $\times 2$.

TEM data were relatively noisy in this particular area, and each TEM model were thus based on only a few gate-times. It is therefore to be expected that resistivity values are relatively uncertain in this interval. The overlying sequence shows low resistivities and appears on the seismic section as an interval with less distinct reflections. In the southern part, the upper boundary of this interval is marked by a reflection (blue horizon), whose reliability could be doubted because of its near-surface position. However, the coinciding transition on the TEM grid to higher resistivities above the reflection indicates that the reflection is not an artifact. In the near-surface from offset $1100 \mathrm{~m}$ to $1700 \mathrm{~m}$ the seismic interpretation (green horizon) of a shallow incision is supported by the position of a high-resistive feature recognised in the TEM data.

Profile C (Fig. 9) is located in the western part of the study area (Fig. 2) along a road where data are influenced by galvanic coupling, which lead to relatively large TEM interpolation distances as illustrated by the black bars on Fig. 9. In the deeper part, resistivities change laterally, showing low values in the west (offset 0$700 \mathrm{~m}$ ) to high values in the east (offset $1200-3000 \mathrm{~m}$ ), whereas the seismic section shows a horizontally-layered sequence. Also here, the deep conducting layer is expected to extend through the entire section. Above this level, the central part of the seismic section seems rather ambiguous with many side-swipes and diffraction hyperbolas, whereas the TEM section shows high resistivities and lower penetration. In the western (offset 0-650 m) and eastern (offset 2450-3000 m) parts of the section, clear reflections and low-resistive areas mark the existence of a series of distinct, but irregular reflections sloping towards the central part of the profile. These reflections can be correlated across the central part of the section on the basis of the resistivity distribution: A conductive layer occur in the SkyTEM data on each side of the chaotic central area and this particular layer is approximately bounded by two of the sloping reflections (marked blue and green in Fig. 9). On top of the conducting layer (above $-25 \mathrm{~m}$ ) in the western part of the section (offset $0-100 \mathrm{~m}$ ) a distinct high-resistive layer occurs. This is most likely sandy deposits, and in the seismic section it appears as an area with less distinct reflections. As also recognised on the other profiles a shallow and rather weak reflection bounds a high-resistive feature from offset $1500 \mathrm{~m}$ to $2500 \mathrm{~m}$. The interpretation of this unit is twofold; while the high-resistivity feature supports the interpretation of the weak reflection, the reflections help delineate the unit.

\section{Discussion}

\subsection{Data aspects}

In the interpretation process it is important to bear in mind the different resolution capabilities of the two methods. As the footprint of the TEM method increases with depth, the spatial resolution decreases equivalently. Furthermore, the considerable size of 


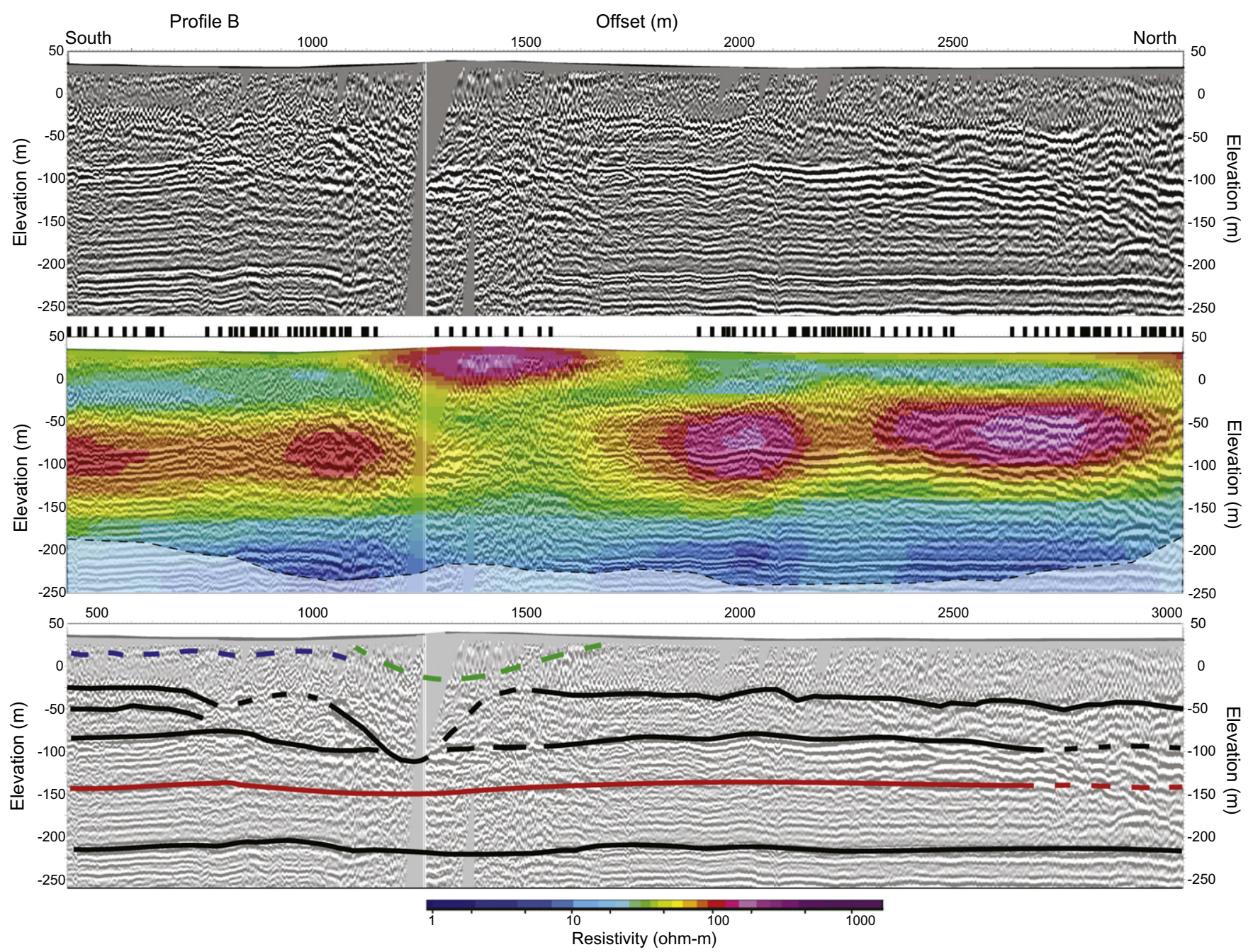

Fig. 8. Profile B. Seismic section (top), TEM grid on top of the seismic section (middle) and interpreted horizons (bottom) based on seismics (black horizons) and TEM and seismics in combination (coloured horizons). In places with reduced signal to noise ratio, horizons are marked with dashed lines. Soundings located within a projection zone of $200 \mathrm{~m}$ are marked as black bars above the TEM grid. The lower part of the TEM section that is deeper than the depth of penetration is shown with reduced colour saturation. Location of the profile is shown in Fig. 2 . The gap in the seismic section stems from a road where seismic data could not be collected. Vertical exaggeration: $\times 2$.

the footprint results in a limited ability to resolve inclined structures. Similarly, the resolution of individual geological layers is significantly decreased with depth and thin layers cannot be resolved at great depths with this method. The seismic method, on the other hand, has a much better resolution that allows for recognition of relatively thin individual layers at all depths. As a consequence of the superior structural resolution of the seismic method it is not to be expected that all the structures revealed by seismic data can be resolved by the TEM data.

When discussing the resolution capacity different issues have to be kept in mind for each method. The quality of raw seismic data can be indirectly observed by studying the quality of traces on the seismic profiles, whereas the number of usable gate-times in neighbouring TEM soundings and the interpolation distances to these soundings typically are obscured. When we co-interpret the two data sets, TEM data are presented as a transparent overlay superposed on the seismic sections. Given that the majority of the seismic lines are measured along roads, the interpreter has to take into account that TEM values shown on the sections are a result of interpolation between the surrounding data points, where spacings of up to $270 \mathrm{~m}$ can occur. Since the TEM footprint increases with depth, the importance of interpolation is most substantial in the topmost part of the profiles. In this way, the rather vague delineation of the high-resistive feature on profile $\mathrm{C}$ (red horizon on Fig. 9) is probably a result of the relatively high interpolation distance between TEM models that show very different resistivity values in this area. Hence, the significance of interpolation distances is highly dependent on the heterogeneity of the geological setting.

The sensitivity of TEM data decreases slowly with depth which is why estimated penetration depths should only be considered as guidelines. The penetration ability is partly dependent on the geological setting and partly on the noise level in the form of the gatetime for the last usable TEM data. During interpretation of deeper parts of the sections, the reliability of TEM data should always be considered.

In the study area, the lithological log shows a thick unit of clayrich sediments below an elevation of $-160 \mathrm{~m}$, where seismic sections appear highly homogeneous with horizontal reflections (Figs. 5 and 7). As this is the case in all seismic lines, it can be expected that deep-lying, clay-rich sediments are present in the entire study area, even though resistivity values fluctuate laterally in the western part. In accordance with this assumption, the majority of sounding curves from the entire area show descending tendencies at late-times. However, in the western part of the area, where the 2006 data are present, the lower signal to noise ratio imply that the information is lost. The influence of the number of gate-times is illustrated by the two synthetic SkyTEM responses 


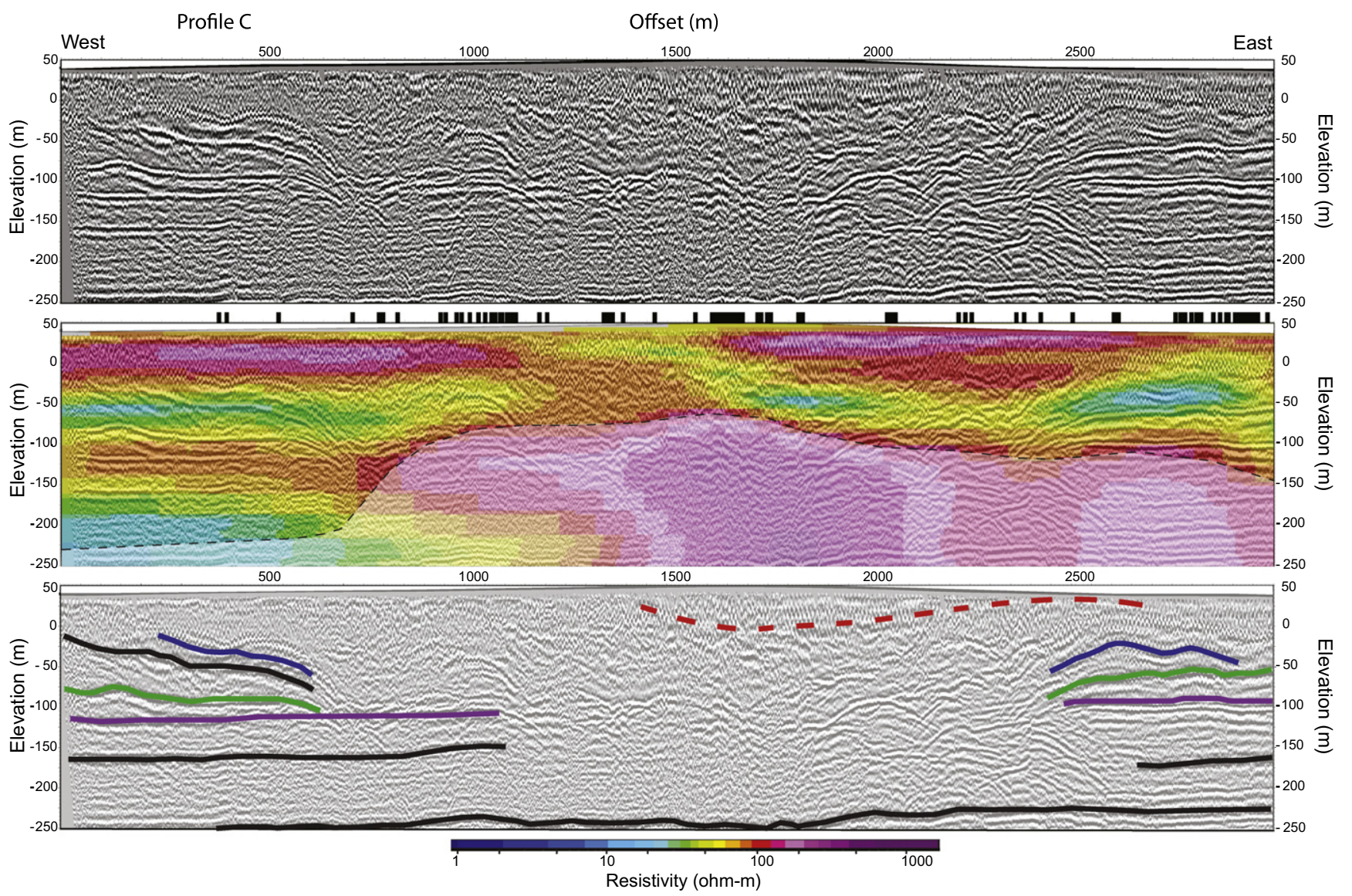

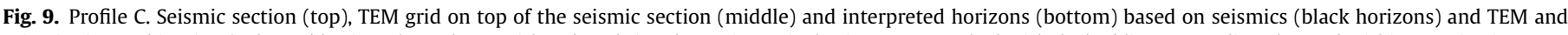

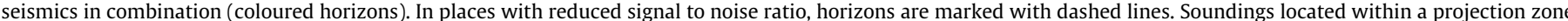

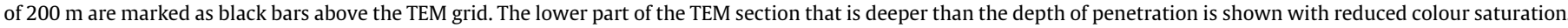
Location of the profile is shown in Fig. 2. Vertical exaggeration: $\times 2$.

in Fig. 5, revealing that a few gate-times more or less can be crucial for resolution of the deeper part in this geological setting.

\subsection{Correlation between reflections and resistivity transitions}

The SkyTEM and the seismic methods measure completely different geophysical parameters. While the seismic method reacts to contrasts in mechanical properties of earth materials, the TEM method is sensitive to variations in electrical conductivity of earth materials. Accordingly, reflections in seismic data appear when differences in acoustic impedances are detected in the subsurface. These differences can occur at boundaries between sedimentary layers, but can also appear in other situations that give rise to differences in elastic properties. Thus, reflections can be recognised in connection with different geological features, such as erosional boundaries and sedimentary sequences, and also internally in homogeneous clayey successions, where reflections can originate by interference from individual weak reflections at closely spaced layer boundaries (Mitchum et al., 1977). When using the TEM method in saturated sedimentary environments without saltwater influence, the method mainly responds to shifts in clay content. In TEM data a horizontally-layered sequence consisting of clay will therefore appear as a single low resistivity layer (like in Figs. 5 and 8), whereas the same setting can give rise to several clear reflections on the seismic sections (Section 6.5). Consequently, the TEM method measures volumes in the subsurface, while the seismic method measures layer boundaries. Therefore gradual changes in lithology are resolvable by the TEM method, while only abrupt changes are recognised in seismic data and with less accuracy in TEM data.

At depth shallower than the estimated penetration depth of the TEM method, the seismic and TEM data in our investigations are generally consistent with each other, allowing several distinct reflections to be correlated with resistivity transitions. However, not all reflections are connected to resistivity variations, and vice versa. This is also evident when comparing the responses of the seismic section and resistivity log to the lithological information (Fig. 5). Thus, some of the marked lithological changes are recognised by both geophysical parameters (e.g. the till deposits), while some of the layers are only seen on the resistivity log (e.g. a clay layer at $-15 \mathrm{~m}$ ) and others only on seismic data (e.g. the clear reflection at $-120 \mathrm{~m}$ ). Consequently, correlation between results of the two data sets is typically found in cases where abrupt boundaries separate layers with different properties in resistivity and acoustic impedance. Accordingly, correlation is not to expect in situations with gradual changes in lithology, or when seismic reflections originate from surfaces that are not connected to resistivity change, e.g. internally in clay-rich successions.

\subsection{Co-interpretation}

In this paper the two data sets were processed independently, since it is our conviction that any co-interpretation should start with a comparison of independent data in order to avoid circular arguments. Because of the better structural resolution of the seismic method, interpretations in 2-D were primarily conducted on 
the basis of seismic sections. However, TEM data act as a support for the delineation and interpretation of seismic reflections and for the interpretation of the lithology between the reflections. Especially in areas with weak reflections, this delineation is very helpful. Seismic data lacks lithological information and even units with the same seismic characteristics can have completely different lithologies. For instance, seismic intervals without distinct reflections are connected to completely different sediments. In some places the intervals are associated with high-resistive units and sandy material (Figs. 5 and 9), while the same type of no reflection interval shows low resistivities suggesting clay-rich sediments in others (Fig. 8). Resistivity information from TEM data are beneficial in providing lithological information about individual units seen on seismic profiles. On the other hand, interpretation of diffuse or noisy TEM data is supported by structural information from seismic profiles (Fig. 9). Also, detailed structural information from the seismic data that cannot be resolved by the TEM method can provide a useful input to the interpretation of high-quality TEM data.

The dense data coverage from SkyTEM surveying provides a unique 3-D impression of the geological setting. It would normally be unrealistically expensive to conduct a seismic survey with the same 3-D resolution. Hence, in a study area like ours, seismic lines should be spaced at $200 \mathrm{~m}$ intervals in the entire study area in order to resolve the complex geology. In cases where seismic horizons can be positively correlated with resistivity transitions, SkyTEM data can be used with advantage to interpolate and extrapolate geological information. For example, SkyTEM data can be used for correlating seismic horizons both internally on seismic sections (Fig. 9) and externally between seismic lines. Even if it were realistic to conduct seismic sections with $200 \mathrm{~m}$ spacing in the entire study area, it would not be possible to achieve spatially distributed lithological information. Certain distinct reflections could be delineated across the area, and a 3-D framework model could hereby be constructed. However, the limited number of existing boreholes in our study area would be inadequate to give the same spatial input on the lithology as provided by the SkyTEM data.

As a consequence of the different geophysical nature of the two methods, correlation of layer boundaries derived from TEM-data with reflections in seismic sections requires independent information that allows for reliable depth conversion of the seismic data. Therefore, a means for depth conversion of the seismic sections together with comprehensive geological knowledge are required in order to justify the implementation of seismic layer boundaries as 'a priori' information in TEM inversions. Especially in cases where data sensitivity is low, implementation of 'a priori' boundaries will lead to models that strictly adjust to this information. This is seen in the study of Shtivelman and Goldman (2000) (Fig. 1), where implementation of 'seismic layer boundaries' in TEM inversions were conducted in order to achieve more realistic geological models.

On the other hand, geological knowledge can be used more indirectly to improve data handling. For instance, knowledge obtained from the combined interpretation of the seismic profiles and the well information could form the basis for inclusion of a deep-lying low-resistive layer in the starting models of TEM inversions in our study area. Another possibility for enhancing the geological reliability of these models could be to strengthen the lateral constraints of TEM inversions in areas and depths where seismic data reflect laterally homogeneous geology.

\subsection{Mapping strategy}

Combined interpretation of SkyTEM and seismic data has proved to be a cost-effective way to conduct reliable geological mapping in complex geological environments like in the Ølgod area. We believe that experiences from Ølgod form a good basis for devising a generally applicable strategy. In the initial phase of a mapping program, dense SkyTEM surveying provides comprehensive 3-D information. This information is used in the second phase to place the more expensive seismic profiles, which in return give detailed 2-D structural information. In the third phase, it is advisable to drill an exploration well in order to support the geophysical interpretation. In this way, resistivities from SkyTEM surveying can be correlated to lithologies, and reliable seismic velocities for depth conversion can be obtained by vertical seismic profiling.

\section{Conclusions}

Generally good correlation between seismic and SkyTEM data is recognised in our study area, and both methods are able to reproduce the sedimentary setting recognised in the well. The seismic data provide detailed structural information in 2-D and resolves layers significantly better than the TEM method - both vertically and horizontally. While no lithological information was obtained from the seismic data, the TEM method indirectly provides lithological information through resistivity values. The TEM method also provides gross structural information, which gives the opportunity for 3-D geological mapping. The penetration depth of the TEM method is important to consider. Estimation of this can be supported by combining lithological information from wells with structural information from seismic lines. The SkyTEM and seismic methods complement each other because they measures different properties. The TEM method supplies both with lithological and 3D information to the seismic interpretation, hereby making it possible to extra- and interpolate along and between seismic lines, while seismic profiles supply with detailed structural information to the TEM interpretation.

\section{Acknowledgements}

The project is funded by The Geological Survey for Denmark and Greenland (GEUS), the Faculty of Science at the University of Aarhus, and Environmental Center Ribe. We would like to thank Steen Thomsen and Clea Schneider from Environmental Center Ribe for helpful cooperation, Per Lynnerup Trinhammer for seismic engineering, Egon Nørmark for help with seismic processing, Christian Dylmer, Sune Colding and Daniel Heubeck for field assistance, Nikolaj Foged and Bjarke Roth for many fruitful discussions concerning SkyTEM data processing, Claus Heilman-Clausen for dating sedimentary samples, Thomas Vangkilde-Pedersen and Jan Piotrowski for discussions on data interpretation and Richard Wilson for his careful improvement of the English language of this paper. Reviews and comments from two anonymous reviewers are greatly appreciated. Finally we would also like to thank Halliburton and Seismic Micro-Technology for allowing us to use their 'Promax' and 'Kingdom Suite' software during this project.

\section{References}

Andersen, S.T., 1965. Interglacialer og Interstadialer i Danmarks kvartær. Medd. fra Dansk Geol. Forening. København 15, 486-506 (in Danish).

Auken, E., Christiansen, A.V., 2004. Layered and laterally constrained 2D inversion of resistivity data. Geophysics 69 (3), 752-761.

Auken, E., Jørgensen, F., Sørensen, K.I., 2003. Large-scale TEM investigation for groundwater. Exploration Geophysics 34, 188-194.

Auken, E., Christiansen, A.V., Jacobsen, L., Sørensen, K.I., 2005. Laterally constrained 1D-inversion of 3D TEM data. In: Symposium on the Application of Geophysics to Engineering and Environmental Problems (SAGEEP), Proceedings, pp. 514518. 
Auken, E., Christiansen, A.V., Jacobsen, L.H., Sorensen, K.I., 2008. A resolution study of buried valleys using laterally constrained inversion of TEM data. Journal of Applied Geophysics 65 (1), 10-20.

Auken, E., Christiansen, A.V., Westergaard, J.H., Kirkegaard, C., Foged, N., Viezzoli, A., et al., 2009. An integrated processing scheme for high-resolution airborne electromagnetic surveys, the SkyTEM system. Exploration Geophysics 40 (2), 184-192.

Binderup, M., Buchardt, B., Gravesen, P., Heilmann-Clausen, C., Holm, L., HoumarkNielsen, M., et al., 2006. Naturen i Danmark; Geologien, first ed. In: Larsen, G. (Ed.), Gyldendal, 549 p. (in Danish).

Bosch, J.H., Bakker, M.A., Gunnink, J.L., Paap, B.F., 2009. Airborne electromagnetic measurements as basis for a 3D geological model of an Elsterian incision. Zeitschrift der Deutschen Gesellschaft für Geowissenschaften 160 (3), 249-258. doi:10.1127/1860-1804/2009/0160-0258.

Büker, F., Green, A.G., Horstmeyer, H., 1998. Shallow seismic reflection study of a glaciated valley. Geophysics 63 (4), 1395-1407.

BurVal Working Group, 2006. Groundwater Resources in Buried Valleys - A Challenge for Geosciences: 303p. Hannover (Leibniz Inst. Applied Geosci.).

BurVal Working Group, 2009. Buried Quaternary valleys - a geophysical approach. Zeitschrift der Deutschen Gesellschaft für Geowissenschaften 160 (3), 237-247. doi:10.1127/1860-1804/2009/0160-0237.

Buselli, G., Lu, K., 2001. Groundwater contamination monitoring with multichannel electrical and electromagnetic methods. Journal of Applied Geophysics 48 (1) $11-23$.

Butler, K.E., Nadeau, J., Parrot, R., Daigle, A., 2004. Delineating recharge to a river valley aquifer by riverine seismic and EM methods. Journal of Environmental and Engineering Geophysics 9 (2), 95-109.

Christiansen, A.V., Auken, E., 2010. A Global Measure for Depth of Investigation. ASEG 2010 - Sydney, Australia. Extended Abstract, 4p.

Danielsen, J.E., Auken, E., Jørgensen, F., Søndergård, V., Sørensen, K.I., 2003. The application of the transient electromagnetic method in hydrogeophysical surveys. Journal of Applied Geophysics 53, 181-198.

Danielsen, J.E., Dahlin, T., Owen, R., Mangeya, P., Auken, E., 2007. Geophysical and hydrogeologic investigation of groundwater in the Karoo stratigraphic sequence at Sawmills in northern Matabeleland, Zimbabwe: a case history. Hydrogeology Journal 15 (5), 945-960.

Deidda, G.P., Ranieri, G., Uras, G., Cosentino, P., Martorana, R., 2000. Joint analysis of seismic reflection and TDEM data to study salt water intrusion phenomena in a coastal area. GNGTS - Atti del 19 Convegno Nazionale, Trieste.

D’Ozouville, N., Auken, E., Sorensen, K., Violette, S., de Marsily, G., Deffontaines, B. et al., 2008. Extensive perched aquifer and structural implications revealed by $3 \mathrm{D}$ resistivity mapping in a Galapagos volcano. Earth and Planetary Science Letters 269 (3-4), 518-522.

Duran, P.B., 1987. The use of marine electromagnetic conductivity as a tool in hydrogeologic investigations. Ground Water 25 (2), 160-166.

Dybkjær, K., 2010. Palynologisk undersøgelse af 5 prøver fra boringen DGU nr. 113.1855 ved Vestkærvej, syd for Ølgod. København. Geological Survey of Denmark and Greenland, GEUS (in Danish).

Fitterman, D.V., Stewart, M.T., 1986. Transient electromagnetic sounding for groundwater. Geophysics 51 (4), 995-1005.

Fountain, D., 1998. Airborne electromagnetic systems - 50 years of development. Exploration Geophysics 29, 1-11.

Gabriel, G., Kirsch, R., Siemon, B., Wiederhold, H., 2003. Geophysical investigation of buried Pleistocene subglacial valleys in Northern Germany. Journal of Applied Geophysics 53 (4), 159-180. doi:10.1016/j.jappgeo.2003.08.005.

Jongerius, P., Helbig, K., 1988. Onshore high-resolution seismic profiling applied to sedimentology. Geophysics 53 (10), 1276-1283.

Jørgensen, F., Sandersen, P.B., 2009. Buried valley mapping in Denmark: evaluation mapping method constraints and the importance of data density. Zeitschrift der Deutschen Gesellschaft für Geowissenschaften 160 (3), 211-223.

Jørgensen, F., Lykke-Andersen, H., Sandersen, P.B., Auken, E., Nørmark, E., 2003a. Geophysical investigations of buried Quaternary valleys in Denmark: an integrated application of transient electromagnetic soundings, reflection seismics surveys and exploratory drillings. Journal of Applied Geophysics 53, 215-228.

Jørgensen, F., Sandersen, P.B., Auken, E., 2003b. Imaging buried Quaternary valleys using the transient electromagnetic method. Journal of Applied Geophysics 53 (4), 199-213.

Jørgensen, F., Auken, E., Lykke-Andersen, H., Sørensen, K., 2003c. Groundwater exploration by use of TEM, reflection seismic surveys and drillings. In: EEGS-ES, 9th Annual Meeting, Prague, Czech Republic. Proceedings Volume 0-063, 4p.

Jørgensen, F., Sandersen, P.B., Auken, E., Lykke-Andersen, H., Sørensen, K.I., 2005. Contributions to the Geological Mapping of Mors, Denmark - A Study Based on a Large-scale TEM Survey. Bulletin of the Geological Society of Denmark, pp. 53-75.

Larsen, G., Kronborg, C., 1994. Geologisk set; Det mellemste Jylland - En beskrivelse af områder af national geologisk interesse, first ed. In: Andersen, S. (Ed.), Geografforlaget, 272 p. (in Danish).

Lykke-Andersen, H., Tychsen, J., 1977. Danien-kalkens overfladetopografi i egnen og farvandet omkring Århus. Dansk Geologisk Forening, Årsskrift for 1976, pp. 6973 (in Danish).

McEwan, K.L., Jolly, I.D., 2006. Vegetation and groundwater interactions on the Bookpurnong floodplain, South Australia. In: Proceedings 10th Murray-Darling Basing Groundwater Workshop: September 2006, Canberra, ACT, p. 7.
Meju, M.A., Fontes, S.L., Oliveira, M.F., Lima, J.P., Ulugergerli, E.U., Carrasquilla, A.A., 1999. Regional aquifer mapping using combined VES-TEM-AMT/EMAP methods in the semiarid eastern margin of Parnaiba Basin, Brazil. Geophysics 64 (2), 337-356.

Miller, R.D., Pullan, S.E., Waldner, J.S., Haeni, F.P., 1986. Field comparison of shallow seismic sources. Geophysics 51 (11), 2067-2092.

Miller, R.D., Pullan, S.E., Steeples, D.W., Hunter, J.A., 1992. Field comparison of shallow seismic sources near Chino, California. Geophysics 57 (5), 693-709.

Mills, T., Hoekstra, P., Blohm, M., Evans, L., 1988. Time domain electromagnetic soundings for mapping sea-water intrusion in Monterey County, California. Ground Water 26, 771-782.

Mitchum, R.M., Vail, P.R., Sangree, J.B., 1977. Seismic stratigraphy and global changes of sea level. Part 6: stratigraphic interpretation of seismic reflection patterns in depositional sequences. In: Payton, C.E., (Ed.), Seismic Stratigraphy Applications to Hydrocarbon Exploration. The American Association of Petroleum Geologists, Tulsa, Oklahoma, p. 516 (Memoir 26)

Møller, I., Søndergaard, V.H., Jørgensen, F., 2009. Geophysical methods and data administration in Danish groundwater mapping. Geological Survey of Denmark and Greenland Bulletin 17, 41-44.

Munday, T., Fitzpatrick, A., Reid, J.E., Berens, V., Sattel, D., 2007. Frequency and/or time domain HEM systems for defining floodplain processes linked to the salinisation along the Murray River. In: 19th Geophysical Conference and Exhibition, Australian Society of Exploration Geophysicists, Extended Abstracts, 4p.

Podgorski, J.E., Kgotlhang, L., Ngwisanvi, T., Ploug, C., Auken, E., Kinzelbach, W. Green, A.G., 2010. Introducing the Okavango Delta, Botswana Airborne TEM Survey, EAGE-NS, Zürich.

Pugin, A., Pullan, S.E., 2000. First-arrival alignment static corrections applied to shallow seismic reflection data. The Journal of Environmental and Engineering Geophysics 5 (1), 7-15.

Pugin, A., Pullan, S.E., Sharpe, D., 1999. Seismic facies and regional architecture of the Oak Ridges Moraine area, southern Ontario. Canadian Journal of Earth Sciences 36 (3), 409-432.

Rasmussen, E.S., Dybkjær, K., Piasecki, S., 2004. The Billund delta: a possible new giant aquifer in central and western Jutland. Geological Survey of Denmark and Greenland Bulletin 4, 21-24.

Rasmussen, E.S., Vangkilde-Pedersen, T., Scharling, P., 2007. Prediction of reservoi sand in Miocene deltaic deposits in Denmark based on high-resolution seismic data. Geological Survey of Denmark and Greenland Bulletin 13, 17-20.

Rumpel, H., Binot, F., Gabriel, G., Siemon, B., Steuer, A., Wiederhold, H., et al., 2009 The benefit of geophysical data for hydrogeological 3D modelling - an example using the Cuxhaven buried valley. Zeitschrift der Deutschen Gesellschaft für Geowissenschaften 160 (3), 259-269. doi:10.1127/1860-1804/2009/0160 0259.

Shtivelman, V., Goldman, M., 2000. Integration of shallow reflection seismics and time domain electromagnetics for detailed study of the coastal aquifer in the Nitzanim area of Israel. Journal of Applied Geophysics 44 (2-3), 197-215.

Sørensen, K.I., Auken, E., 2004. SkyTEM - a new high-resolution helicopter transient electromagnetic system. Exploration Geophysics 35 (3), 191-199.

Sørensen, K.I., Thomsen, P., Auken, E., Pellerin, L., 2001. The effect of coupling in electromagnetic data. In: Proceedings - Electrical and Electromagnetic Methods Session (ELEM), Birmingham, England, EEGS, pp. 108-109.

Steeples, D.W., Miller, R.D., 1990. Seismic reflection methods applied to engineering, environmental, and ground-water problems. In: Ward, S.H., (Ed.), Geotechnical and Environmental Geophysics, vol. 1. Review and Tutorial. Society of Exploration Geophysicists, Tulsa, Okla., pp. 1-30.

Steeples, D.W., Schmeissner, C.M., Macy, B.K., 1995. The evolution of shallow seismic exploration methods. Journal of Environmental and Engineering Geophysics 0 (1), 15-24.

van der Veen, M., Green, A.G., 1998. Land streamer for shallow seismic data acquisition: evaluation of gimbal-mounted geophones. Geophysics 63 (4) 1408-1413.

van der Veen, M., Buness, H.A., Büker, F., Green, A.G., 2000. Field comparison of high-frequency seismic sources for imaging shallow $(10-250 \mathrm{~m})$ structures Journal of Environmental and Engineering Geophysics 5 (2), 39-56.

van der Veen, M., Spitzer, R., Green, A.G., Wild, P., 2001. Design and application of a towed land-streamer system for cost-effective 2-D and pseudo-3-D shallow seismic data acquisition. Geophysics 66 (2), 482-500.

Vangkilde-Pedersen, T., Skjellerup, P., Ringgaard, J., Jensen, J.F., 2003. Pulled array seismic (PAS) - a new method for shallow reflection seismic data acquisition. EAGE, Stavanger.

Vangkilde-Pedersen, T., Dahl, J.F., Ringgaard, J., 2006. Five years of experience with landstreamer vibroseis and comparison with conventional seismic data acquisition. In: Symposium on the Application of Geophysics to Engineering and Environmental Problems (SAGEEP), Proceedings.

Viezzoli, A., Christiansen, A.V., Auken, E., Sørensen, K., 2008a. Quasi-3D modelling of airborne TEM data by spatially constrained inversion. Geophysics 73 (3), F105F113.

Viezzoli, A., Christiansen, A.V., Auken, E., Sørensen, K., 2008b. Spatially Constrained Inversion for Quasi 3D Modeling of AEM Data. In: Symposium on the Application of Geophysics to Engineering and Environmental Problems, pp. 104-108 (Eegs). doi:10.4133/1.2963212.

Yang, C., Tong, L., Huang, C., 1999. Combined application of dc and TEM to sea-water intrusion mapping. Geophysics 64 (2), 417. 